\title{
25 CONSTRUCTING INTERDEPENDENCIES WITH COLLABORATIVE INFORMATION TECHNOLOGY
}

\author{
Helena Karsten \\ University of Jyväskylä
}

Finland

\begin{abstract}
Interdependence construction is the gradual formation of mutual relationships between people. In this study, the area is narrowed to interdependencies at work, in long term projects or groups. Viewing interdependence relationships dynamically, as social practices, it is possible to appreciate the complex and situated nature of this formation. The main goal of the study is to develop a theoretical account of the dynamics of the intertwined processes of interdependence construction and collaborative technology appropriation and use. The main dimensions of this account are: (1) how interdependence is constructed and established as a social process, (2) how information and communication are involved in these processes, and (3) in what ways collaborative information technology can contribute to or hamper these processes. Three earlier case studies are revisited using it. The theoretical approach opens up an extensive research program of interdependence construction in relation to collaborative information technology appropriation and use.
\end{abstract}

Keywords: Interdependence, collaboration, collaborative information technology, structuration theory, information, communication

The original version of this chapter was revised: The copyright line was incorrect. This has been corrected. The Erratum to this chapter is available at DOI: 10.1007/978-0-387-35505-4_33 


\section{Introduction}

Interdependence construction is the gradual formation of mutual relationships between people. In this study, the area is narrowed to interdependencies at work, in long term projects or groups. Thus, the interdependencies to be studied here concern doing something together over a period of time. Interdependence construction and its reverse, interdependence dismantling, take place continuously in organizations, for example, when task forces or project organizations are formed, or when work tasks are reorganized.

Traditionally, interdependence relationships have been looked at from two perspectives, either as interdependence between people or as interdependence between work tasks (Mintzberg 1979: workflow, process, scale, and social interdependencies). In separating work tasks and people, these perspectives provide only relatively narrow and clear cut views on what could be assumed to be a wide variety of forms and appearances. They also may remain insensitive to the complex and situated nature of interdependencies (Weick 1979). Most importantly, they may lead to a static view of what may be a very dynamic relationship.

In this study, therefore, the focus is on social practices: the relationships are not considered separately, but the attention is on people engaging in action and interaction. Interdependencies are then seen as constantly constructed and reconstructed social practices (Giddens 1984), that is, repetitive, patterned, and reciprocal action and interaction (Weick 1979, p. 46). Interdependence construction is then creating or reconstructing patterns of action and interaction where two or more people are mutually dependent on each other.

Interdependence construction may be expected to take different forms when the relationships are mediated. The mediator of interest in this study is collaborative information technology (CIT). CIT is a label used to denote the kinds of asynchronous groupware where the designers' intent is to provide support for coordination and collaboration through group access to technological capabilities such as shared repositories, discussion forums, and communication facilities (Orlikowski 1995). The purported "collaboration-inducing facilities" of CIT have been identified as related to their capabilities to support high levels of interaction, many-to-many communication and information sharing, in a group of known users, across hierarchical, divisional, or timegeographic boundaries (Coleman 1996; Dyson 1990).

When interdependence relationships are seen as social practices, the focus of interest shifts to the process through which these relationships are formed and reconfigured. The role of technology, in this case "installations of CIT," needs to be considered in parallel, since, as is widely argued (Button and Sharrock 1997; Haraway 1991; Joerges 1988; Latour 1993; Sproull and Kiesler 1991), the social process and the technical system cannot be considered separately. The view in this study is that CIT can be used to support interdependence construction via its capabilities. These capabilities do not necessarily lead to interdependence construction, but rather they may become heavily involved in a variety of ways as they become woven into the social practices of the users. It is contended that a richer understanding of interdependence construction in relation to CIT appropriation and use can be achieved by carefully dissecting their intertwined dynamics. The goal of this study is to form a theoretical account of these dynamics. 


\section{Earlier Studies}

Several studies acknowledge that CIT appropriation and use is influenced by the "fundamental and sometimes subtle social processes in work" (Kling 1991, p. 84), which, when ignored, can contribute to the failures. These social processes are said to include user innovativeness (Swanson and Ramiller 1997), learning through use (Attewell 1992), improvising (Orlikowski 1996) or bricolage (Buscher and Mogensen 1997), among others. If these social processes are seen as adjustments and modifications both in technology and in people, they include mutual adjustments in user organization and the CIT system (distributed processes of co-evolution, Rogers 1994) and establishing congruence (Prinz, Mark, and Pankoke-Babatz 1998) in the user group, and between users and designers.

Prinz, Mark, and Pankoke-Babatz also claim that congruence cannot be achieved unless designers and users achieve a common understanding of users' tasks, work processes, and system design. In their three-year case study, they found that after two years of CIT use, when the work patterns had become seemingly firmly established, the group members began to report problems that concerned coordinating their work patterns. Their interpretation was that at this point the group members were beginning to recognize the consequences of their mediated interdependencies. "This suggests that only with continued system use, the users gradually become aware of how others' actions were affecting their own system use, and they adjusted and accommodated their behaviors accordingly" (Prinz, Mark, and Pankoke-Babatz 1998, p. 377). Thus these studies also point to the relevance of studying the intertwined processes in parallel even though they do not explicitly tie interdependence construction to capabilities of CIT.

Very few empirical studies have so far discussed the microsocial dynamics (Barley 1990) of how interdependencies are constructed or reconfigured and how these processes are tied to CIT appropriation or use. Three detailed, longitudinal studies, by Orlikowski and others (Orlikowski 1996; Gallivan et al. 1993), Ngwenyama (1996, 1998), and myself (Jones and Karsten 1997; Karsten 1995, 1999; Karsten and Jones 1998) are taken here as examples. The studies by Orlikowski (Zeta) and Ngwenyama (Eiger) do not focus explicitly on it either, but, in both cases, intensified interdependence construction is visible through the increased density and complexity of organizational relationships and the emerging novel kinds of interdependency relationships. The data in my own case, $\mathrm{CCC}$, also covers CIT appropriation and interdependence construction. Due to space constraints, each of these is presented only briefly below. For more information, the reader is referred to the articles mentioned.

In Eiger, a Lotus Notes application was introduced to automate processes of managing software development that had been distributed across three continents, to take advantage of time differences. Ngwenyama reports a number of expected and unexpected changes. The groupware application, ADM, was based on the application development methodology that was well established in the company. Initially, the methodology was implemented in a quite straightforward way in Notes. This had unexpected consequences as the work practices could deviate considerably from the inscribed methodology, and the application had to be modified. Also, as the team members learned of the capabilities of the program, they started to make proposals for embedding layers of intelligence into the application. The ADM application served both as a medium of work and as a medium of social interaction. Lateral communication increased between designers and programmers across the three continents. Many of the events in CCC during the period studied were colored by a deep recession and slow recovery from it. 
In Zeta, a software company, a Lotus Notes application, ITSS, was introduced to manage helpdesk calls. In addition to planned changes, a number of ongoing local improvisations took place, in response to deliberate and emergent variations in practice. The specific changes that Orlikowski reported include changes in the nature and texture of work (from tacit, private, and unstructured to articulated, public and more structured); patterns of interaction (from face-to-face and reactive to electronic and proactive); distribution of work (from call-based to expertise-based); evaluation of performance (from output-focused to a focus on process and output as documented); forms of accountability (from manual and imprecise to electronic and detailed); nature of knowledge (from tacit, experiential, and local to formulated, procedural, and distributed); and mechanisms of coordination (from manual, functional, local, and sporadic to electronic, cross-functional, global, and continuous). The specialists started to take shared responsibility for the whole team performance by contributing where they could, and by offering their expertise for use by others outside their team. They began to intervene in each others' work as prompted by the organization but also at their own initiative. By this, their interdependence changed its nature to become proactive and perhaps even coercive.

The third case, $\mathrm{CCC}$, is about a small Finnish computer consulting company. Much of the events in CCC were colored by the deep recession in Finland during 1991-1993, by several changes in company management, including three different managing directors, by radical overhaul of expertise by several consultants, and by gradually increasing participation by the consultants. Notes use became gradually focal to new organizational practices, including mutual help in winning and coordinating projects, and a consensual management style, with all the consequent changes. In terms of coordinating and winning projects, the main results were increased horizontal and vertical coordination. Mutual visibility led to horizontal coordination and eventually to a higher degree of horizontal integration through an increase in joint projects. The applications also assisted vertical coordination, by providing a project history which could be consulted if a project had to be transferred to another consultant.

In the cases above, the relationship between CIT appropriation and interdependence construction reveals its complexity. The relationships appeared to have to do, among other things, with certain kinds of use practices, which included disclosure of information beyond the immediate users, (construction of) mutual responsibility for the work in the user community, and immediate access to the information, regardless of the physical locale. The users appropriated the technology, because it gave the kind of information and communication tools that were useful in their work and established them as members of the community. Nevertheless, these cases indicate a need to study the interdependence relationship more closely, as the earlier accounts do not discuss what exactly were the capabilities and use practices in these installations, how they were connected, and how the interdependence relationships emerged in relation to the new capabilities and the changed use practices.

To achieve such an understanding of the social processes of interdependence construction, structuration theory (Giddens 1984) is used as the basis for a theoretical account of interdependence construction, which is then connected via information and communication to CIT capabilities. As this is a first presentation of the emerging theoretical account, the emphasis is placed on laying out its rudiments. Relating this work to the vast bodies of relevant literature (such as computer mediated communication, knowledge management, information access, surveillance, etc.) has been left to a large extent for later refinements of the model. 


\title{
3. Interdependence Construction as Social Process
}

\subsection{Overview of the Emerging Theory}

As the earlier studies show, the relationship between interdependence construction and CIT appropriation and incorporation is complex. This work introduces rudiments of a theory that seeks to encompass that complexity and outline the social processes involved (see Table 1 for a first characterization of the emerging theory). Drawing on Giddens' $(1979,1984)$ structuration theory, four interrelated aspects of interdependence construction-social integration, time-space distanciation, institutionalization, and system integration - are brought forward.

\section{Table 1. The Four Aspects of Interdependence Construction and Their Relationship to Information and Communication (Following Giddens 1979, 1984)}

\begin{abstract}
Social Integration
Origins of interdependence construction lie in social integration, in the systemness of interaction or interdependence in action. This is possible not only in face-to-face situations, but also via situated mediated communication.
\end{abstract}

\section{Time-space Distanciation}

For a socially integrated system, stored resources provide a means for time-space distanciation, for extending beyond the present time and place. Stored resources are managed with related information and communication, which are in this way anchored into a context and made significant.

\section{Institutionalization}

Institutionalized relationships are routine and regular. Institutionalization builds on active and chronic reproduction and on past interactions. If the history of interaction is available in an accessible form, it can increase the transparency of the practices and provide a growing archive of information that can be referenced to further ground the relationships.

\section{System Integration}

Practices of reciprocity in information access and maintenance between interacting communities may increase their mutual closeness via ownership and responsibility for information. Surveillance and disclosure allow for control and visibility from afar. Together, these change the nature of the systemness of interaction, extending it from social to system integration. 
According to Giddens, these four aspects can rely on information and communication in special ways, as outlined below. The role of collaborative information technology could then be to act as a mediator for communication and as a provider of information storage, plus possibly as a provider of other CIT-specific capabilities. These three dimensions - the four aspects of interdependence construction; information and communication that may play a role in it; and CIT as providing mediation and storage - do not form an exhaustive framework to explain evolving groupware use. My goal in bringing them up is to draw attention to the gradual and complex nature of interdependence construction, i.e., to the subtleties of interaction involved, the specifics of information and communication in this, and to how the capabilities and uses of CIT may be involved in the process.

Each of the three dimensions of the emerging theory will be treated differently in the following discussion. The four aspects will be directly drawn from Giddens and related social theory, and they form the basis for further work. The role of information and communication is discussed based on Giddens, but the discussion is extended in the light of IS research. The third dimension of the theory - what all this has to do with collaborative information technology - will be first visited when information and communication are discussed. However, the three cases will provide much more richness into this dimension and, therefore, their role is emphasized, as the goal is to achieve empirically grounded insights into the relationships between the social processes, information and communication, and CIT introduction and use.

\subsection{The Four Aspects of Interdependence Construction}

The starting point in studying change processes is the basic idea of how something remains the same and something else may change. In Giddens' (1979, 1984; Jones 1999) structuration theory, stability and change are approached from the idea of the duality of structure: each action draws upon the structures that enable and constrain it and by this each action also contributes to reproducing or changing the structures (Giddens 1984, pp. $25-29 ; 297-304)$. Structures refer here to the intersubjective structures of social existence, held by the individuals participating in these social practices. Structures indicate to an individual how she or he should act as a member of a particular community. Recently, Giddens has called these structures "conventions" (Giddens and Pierson 1998, p. 87), which gives a useful, even though simplified, common sense idea of them.

Giddens extends his theory of social systems then to how the individuals become members of the community. He uses the sociological terms of social and system integration to examine mechanisms of interdependence construction. Social and system integration both refer to how social systems - such as work groups, organizational departments, or professional associations - gain their systemness in relation to the people within the system and in relation to other social systems. That is, social and system integration are the counterpoint of the duality of structure. Together, they seek to explain how it is possible to have at the same time discernible stable patterns of action in a community and a possibility for change. Time-space distanciation is used to explain how these patterns survive beyond the present time and place. Institutionalization then is the process by which the patterns of action become regularized and routinized. Together, 
these four aspects explain how social practices such as interdependence relationships are created and established. However, these aspects are not phases, there is no sequence between them. Human actions that contribute to these aspects of interdependence are parallel and interspersed. Therefore, interdependence construction is a process where all these aspects are present, more or less. Before going on, each of the aspects will be discussed in more detail.

Social integration is what makes a group of people a school class or a work team. Giddens' starting point in discussing social integration (Giddens 1979, pp. 76-81; 1984, pp. $28 ; 89 ; 191)$ is face-to-face communication, which is generally considered the primary, immediate mode to which other, mediated modes are compared (Berger and Luckmann 1967, pp. 43-48; Giddens 1984, pp. 64-72). In meeting face-to-face, in situations of co-presence (Goffman 1972), the other person is accessible as a person with a physical body, with bodily expressions, giving the interaction a density in reciprocity that is difficult to achieve in other kinds of interaction. Social integration is then the systemness of this densely reciprocal interaction, the interdependence of action, between the co-present actors. That is, social integration concerns patterning of interaction, knowledge about how the others will act, and the potential predictability of interaction.

Time-space distanciation (Giddens 1984, 256-262) refers to the ability of social systems to exist beyond the immediate here and now; that is, how interdependence relationships carry beyond the immediate interaction, how they persist. He defines it as the "stretching of social systems across time-space, on the basis of mechanisms of social and system integration" ( $p$ 377). That is, the systemness of interaction between people and between social systems, resulting from its dense reciprocity, is a necessary mechanism for social systems to be able to exist beyond the immediate here and now. The greater the time-space distanciation of social systems, the more their institutions "bite into time and space" (Giddens 1984, p. 171).

The systemness of interaction gradually becomes routine, and its discernible, even distinct, patterns become regular. Berger and Luckmann call this institutionalization, which they define as "reciprocal typification of habitualized actions by types of actors" (Berger and Luckmann 1967, p. 72). The institutionalized practices of interaction exhibit the structural properties of the particular relationships, which constrain and enable their reproduction. At the same time, they exist as such only as a result of active and chronic reproduction. To quote Giddens (1984, p. xxi): "The structural properties of social systems exist only in so far as forms of social conduct are reproduced chronically across time and space." Continuity is the key here.

The fourth dimension of how interdependence relationships become established is system integration, which has been characterized as systemness of interaction outside the conditions of co-presence (Giddens 1984, p. 377). An earlier characterization (Giddens 1979, pp. 76-81), however, defined system integration as reciprocity between groups or collectivities, without regard for physical presence or absence. My understanding is greatly influenced by the earlier version, even though the later version seems to be adopted in IS research (e.g., Lyytinen and Ngwenyama 1992; Ngwenyama 1998). The later definition, however, has the danger that it may encourage a misunderstanding of (computer) systems integrating collectivities across space and time. For the current discussion, the emphasis on reciprocity between collectivities as system integration is focal. Therefore, in this work, system integration is used to refer to systemness of reciprocity between groups or collectivities. 


\subsection{Information and Communication in Interdependence Construction}

\subsubsection{Social Integration and Situated Mediated Communication}

The face-to-face interaction that was deemed necessary for social integration is not without problems. It is intensive, synchronous, and time-consuming as compared to mediated interaction, which can be asynchronous, can span a longer period of time and space, and where periods of communication can be interspersed with other activities when suitable. The question then is to what extent mediated communication can replace or supplement face-to-face communication when a higher level of social integration is desired.

Giddens (1984, p. 68) admits that it may be possible to simulate some of the "intimacies of co-presence," some of the closeness of face-to-face encounters, in mediated communication to facilitate social integration. Letters carry some of the presence of the letter writer, and in telephone conversations, the other party can be heard. This observation gives a starting point for also studying computer mediated (and hence also CIT mediated) communication in terms of social integration.

In the IS literature, the primacy of face-to-face interaction, and the problems with mediated communication in terms of density in reciprocity have commonly been addressed under the label of media richness. Daft and Lengel $(1984,1986)$ initiated discussions of the bandwidth that would be sufficient for various kinds of interaction. Prinz, Mark, and Pankoke-Babatz (1998) gave a common explanation of this dilemma by stating that the difficulty that electronic groups face during system use is that they lack the social information that groups generally gain through formal and informal face-toface interaction.

However, empirical data (e.g., Dennis and Kinney 1998; El-Shinnawy and Markus 1998; Kock 1998) show that social integration also is possible with computer mediated communication, even though it might be more difficult than in face-to-face communication. These results suggest that sufficient social information can be conveyed in electronically mediated interaction. Moreover, the results indicate the importance of situatedness of interaction. Situatedness here means that interaction takes place in the context of particular, concrete circumstances (Suchman 1987, p. viii). In situated interaction, the group is able to share both task related information and communication. When they can also exchange social information, they are able to adjust their interaction, which then, over time, can achieve the density and systemness in reciprocity, necessary for interdependence.

\subsubsection{Time-space Distanciation and Stored Information}

Giddens (1984, pp. 256-262) connects time-space distanciation to his theory of power. Power is defined as the capacity to achieve outcomes and it is generated in and through the reproduction of structures of domination. Giddens emphasises storage of resources as a medium for domination. Stored resources, both material and symbolic, bind timespace involving "the knowledgeable management of a projected future and recall of an elapsed past" (p. 261), that is, with stored resources the social relations can be carried 
beyond the particular situations. In other words, one reason why social systems such as work teams and school classes persevere even when the people are not together in the same place at the same time is because they are tied together by stored resources such as the object they are working on (e.g., a joint memorandum, a piece of art) and their tools for that, "their room" with its facilities, or a person whom they consider their leader. This view of Giddens seems defensible especially when stored resources are seen to include also symbolic resources, such as reputation or mission.

Retention and control of information, among other things, contribute to storage of resources. In Giddens' words: "the storage of authoritative and allocative resources may be understood as involving the retention and control of information and knowledge whereby social relations are perpetuated across time-space" $(1984$, p. 261). He emphasizes that "information storage...is a fundamental phenomenon permitting timespace distanciation and a thread that ties together the various sorts of allocative and authoritative resources" (p. 262).

By discussing "stored information" instead of stored data, Giddens can be seen to draw attention to the contextuality and assigned significance of the information, gained by its connection to the stored resources, as opposed to detached pieces of data. Equally, we can discuss mediated, stored communication instead of stored messages, when communication is tied to the information that communication is about. By this, separate messages gain their significance as parts of communication about this piece of information, as contextual communication. Access to and control of these is significant: contextual information and communication also implies access to the stored resources.

Giddens points out that the stored information requires a means to carry, recall, and disseminate it (that is, for storing and communicating it), in addition to skills for interpreting it. The dissemination of information is influenced by the technology available for its production. Giddens uses the example of mechanized printing (p. 262), which conditions what forms of information are available and who can make use of it; that is, its accessibility. The one who has access to the information and who can control it, has access to the stored (material and symbolic) resources. With technical aids, such as CIT, this accessibility can be interpreted in a very concrete way to mean access to the data and messages in the databases, embodying the information and related communication.

It can be claimed that by use of CIT, the stored information and communication can become highly accessible, as compared to, for example, when it is stored in paper files and folders in an office. First, because reading and browsing the stored information and communication is not necessarily noticeable to others, thus learning by lurking, i.e., by legitimate peripheral participation, is possible (Lave and Wenger 1991). Second, because access to CIT can be implemented in such a way that users can use it at their own discretion, when and where it suits them (Connolly and Thorn 1990). Third, because the stored information and communication can be permanently and publicly accessible.

This third reason warrants some elaboration. Information and communication, the data and the messages, can be stored in various forms, but the major way of conveying information in organizational life is still by writing. To quote Goody (1987, p. 280), "The written language (reaches) back in time." Written artifacts can at any time be mobilized as a referential object for clarifying ambiguities and settling disputes: "while interpretations vary, the word itself remains as it always was." Schmidt (1997) also draws attention to the permanence and public character of written records: "They are, for all 
practical purposes, unceasingly publicly accessible." Information in files and folders in the office are also permanent and public records. Information in CIT differs from that in files and folders not only due to the accessibility, but also because other ways of presenting the information, such as video or audio, are tied together. For these reasons, CIT can be seen as potentially significantly relaxing the conditions of access.

\subsubsection{Institutionalization and History of Interaction}

Institutionalization of interdependence relationships, that is, how the interaction becomes routine and regular, depends, on one hand, on its active and chronic reproduction. On the other hand, it also depends on past interactions, on its own history. The patterns of interaction contain traces of these past interactions in the form of structures that people employ in conducting the interaction. The history of interaction can also be more transparently available, for example, a written account, to be used as a resource in carrying out the interaction. This history of interaction may provide an opportunity to ground the practices of interdependence further, as the interdependent participants can have more background and may be better informed about how to go on (mutual knowledge, Giddens 1984, p. 375).

CIT can contribute to institutionalization in several ways. Practices can become increasingly transparent if both present and past actions are visible in the stored information and communication (cf. with the idea of informating by Zuboff 1988). Also, the archive of information can gradually become substantial and in this way become a significant source of information.

CIT mediated interaction can be a special case in at least two ways. One way is that the messages can remain as entries in the databases, and in this way the flow of communication can become stored information. The messages can be either connected to each other by message header information such as time stamps, or they can appear as threaded messages, showing the first entry of a discussion and replies and comments connected to it. By tracing the messages, an account of the history of the discussion can be constructed.

\subsubsection{System Integration and Reciprocity}

Issues of reciprocity and of surveillance and disclosure relate closely to system integration. They can play a role in the move from social to system integration as the interacting parties can be communities and not only individuals. From the perspective of the interacting communities, they enable confidence to be maintained in the other party.

Reciprocity may include mutual access to, and disclosure of, relevant and significant information, and as a possible consequence, mutual maintenance of the information. Zuboff (1988, p. 356) has interpreted mutuality to imply equality of access and the presence of sufficient depth of intellectual skill so that those who have access to data also have access to their meaning. Others (such as Giddens 1984, p. 127; Poster 1990, 1995) have emphasized not equality but the negotiated nature of the forms of reciprocity in each case. 
When information is maintained together, the nature of information use and thereby also practices of reciprocity may change, and mutually maintained information can become even more closely tied to action and interaction. By mutual maintenance, the quality and credibility of the information can gradually improve, in terms of its assigned purpose (VanHouse, Butler, and Schiff 1998). Perhaps mutual maintenance is then the key in explaining how ownership and responsibility for information evolve.

Negotiating access to information involves at the same time also negotiating the extent and boundaries of surveillance (Clement and Wagner 1995). Similarly, the extent of disclosure illustrates compliance to being subject to surveillance. Giddens sees surveillance as unidirectional, creating a non-equal relationship between two collectivities, as one group can control the other group by it. Thus with surveillance, the nature of the relationship changes, Giddens argues, from solely a social relationship to one including the system dimension by the visibility and control aspects from afar. In terms of time-space distanciation, this means persistence of the social system also in relation to other social systems.

\section{Review of the Cases}

\subsection{Social Integration and Situated Mediated Communication}

These elements and issues of the emerging theory of the relationship of interdependence construction and CIT will now be used to revisit the three cases described earlier. This brief and far from thorough "analysis" is mainly aimed at illustrating ways in which the theory can be used to inform reading and understanding the cases.

Eiger provides an example of the way that situated mediated communication contributed to social integration. In addition to communicating about tasks at hand, users in the USA, Asia, and Europe became more informal in their mutual relationships, exchanging weekly chit chat and updates about their lives. Ngwenyama (1998, p. 141) refers to this as social integration. His usage of the concept differs from that of Giddens, for whom social integration lies in interdependence of action, not only in acquiring social information.

Social integration in the Giddensian sense can be discerned by going further into the systemness that gradually emerged, as the familiarity then spread to the task-related communication, which became gradually freer, and where opinions were exchanged across continents. For example, the Asian team members, who did the programming, became more visible as people with considerable skills, and their views were taken more into account. The Asians felt more a part of the team, as they were more involved in discussions, and not just receiving orders: "Now we know what they are doing and they know what we are doing." Thus their interaction had gained its systemness in a recursive fashion: familiarity spread from social to task-related interaction, which became more interactive leading into more familiarity and reciprocity.

Neither Zeta nor CCC provided clear examples of social integration with solely mediated communication. In both cases, there was also a physical locale where the people could and did meet. They were not fully dependent on any single medium to communicate. In Zeta, however, the people started to prefer electronic communication 
because it was experienced to be less intrusive. As the electronic interaction reduced faceto-face interaction during the course of the day, it was then compensated for by arranged get-togethers.

In CCC, patterning of interaction with Notes was slowed because it took 13 to 14 months before all people in the group were users. This was different from Eiger and Zeta, where the application needed to be used by the whole group, or not at all. The systemness of interaction in Notes discussions emerged gradually, as Notes started to contain whole discussions, and not just to supplement discussions in meetings. Notes was used to discuss joint decisions, such as hardware and software investments, to gather everybody's views, and to reach an agreement. This practice of taking everyone's view into account gradually became so well established that, for some issues, the third managing director mentioned to avoid Notes as it was "too democratic." A major reason for this democratic use, as stated by several consultants, was that, with Notes, one could participate in the discussion at one's leisure and the pace allowed both quick and slow, quiet and verbose, people to enter their views. The situatedness of the interaction became, in a way, stretched over time.

The suggestion that social integration was supported by the situatedness of the communication together with social information, rather than the particular media employed, found backing in all of the cases. As long as all members of the group had access

Table 2. The First Dimension: Social Integration

\begin{tabular}{|c|c|}
\hline $\begin{array}{l}\text { Dimension of } \\
\text { interdependence } \\
\text { construction: social } \\
\text { integration }\end{array}$ & $\begin{array}{l}\text { What kind of information and communication is } \\
\text { involved? } \\
\text { Situated communication with social information. }\end{array}$ \\
\hline $\begin{array}{l}\text { Specifics of CIT: } \\
\text { Provides mediated } \\
\text { channel for situated } \\
\text { communication, which } \\
\text { can include social } \\
\text { information. }\end{array}$ & $\begin{array}{l}\text { Social integration in the cases: } \\
\text { Electronic communication became sufficiently dense } \\
\text { and reciprocal in all three cases to support social } \\
\text { integration. } \\
\text { Situated interaction was present in all cases, but social } \\
\text { information only in Eiger, where there was no } \\
\text { opportunity for face-to-face meetings. } \\
\text { Additional insight provided by the cases: } \\
\text { Eiger: Social information was tied reciprocally to task- } \\
\text { related communication. } \\
\text { Zeta: Mediated communication preferred as less } \\
\text { intrusive. Acknowledgment of need for different, } \\
\text { complementing channels of communication. } \\
\text { CCC: "Democratic participation" became possible } \\
\text { when the media allowed all to participate. Situatedness } \\
\text { of interaction became in a way stretched over time. } \\
\text { Different media and changes of media gave } \\
\text { possibilities for disintegration. }\end{array}$ \\
\hline
\end{tabular}


and used the same media for discussing joint issues, the particular media choice was not decisive for interdependence construction. Moving from one medium to another, however, took place in passages of transition during which the group could also show symptoms of disintegration. For example, in CCC, there was a period when those not yet using Notes feared that the discussions and information in Notes would somehow serve only the Notes users, whom they already considered to be in the "inner group" and holders of much information. The "outsiders" feared that the same information would then not be distributed to them. This division disappeared when, with access to sufficient technical equipment, everybody could read the entries regularly.

\subsection{Time-space Distanciation and Stored Information and Communication}

The significance of contextual communication is perhaps best illustrated in Zeta. Information about the phone calls from customers and the help desk specialists' communication around these was significant for creating and managing interdependencies between the specialists. With this, requesting and giving help about a specific problem were possible. Also in Eiger, the information and communication about the software project at hand were significant for coordinating the work of the teams in different countries. Likewise, only within the context provided by the application development methodology could the information gain its specific significance.

In Eiger and in Zeta, all information and communication regarding the software project and the customer calls had become highly accessible to all concerned, as they had started to use the CIT at the same time for the same purpose. The consequences of this accessibility give interesting insights into how the interdependency relations were reconfigured with CIT. In Zeta, the specialists began to assist each other proactively, without request, based only on what they saw in the Notes databases. The specialists also began to put together summaries of common problems they had solved and make them available in other help desk groups. These new practices reflected their awareness of shared responsibility for calls, and they could be interpreted as involving considerable interdependence creation. They can also be interpreted as reconfiguring the interdependence relations from reactive to proactive, and using CIT to facilitate the changed demands for information accessibility.

In Eiger, the initially very strict rules in the ADM application dictated what information and communication were significant. Gradually, the actual practices took over and the rules in the ADM application were modified to correspond to these. In parallel, the practices became adjusted to take advantage of the free communication and the interaction started to include social chat. That is, the ADM application with the related information and communication made the resources not only accessible, but also discussable, and these discussions started to include social aspects as well. In this way, communication gained new dimensions. The interaction became denser in reciprocity and thereby (by definition) more interdependent.

In $\mathrm{CCC}$, the situation was different. The key resources were project leads and current projects. However, some did not see these as significant for themselves, as they were already fully employed. Only during the recession, when the information about leads and 
projects was reinterpreted as reflecting the success of the whole company, did it became significant for all, as the consultants were also shareholders in the company and, therefore, interested in its fate. Thus not only availability of the information in Notes databases, but also the possibility of reading the information as anerview (Robinson 1991) of the situation provided an incentive to read and maintain information. An overview is an aid to understanding constantly changing context. It is the best way of situating action-realizing the agenda set out in the plan - within this flux of context. CIT facilitated this by providing not only higher accessibility but also by offering different views into and summaries of the information.

As we saw, high (levels of) accessibility of stored information and communication had a number of consequences. The information and communication were likely to gain attention as they were significant. Access also brought division among those who had access - directly or indirectly - and to those who did not. When the information was useful, joining those who had access became more appealing than staying outside. Other studies (VanHouse, Butler, and Schiff 1998) have also shown that when information and communication are significant and highly accessible, they are also likely to be more controllable, and this control can contribute to improved quality and accuracy of the information. Also, practices to assess its credibility can be established.

\section{Table 3. The Second Dimension: Time-space Distanciation}

\begin{tabular}{|c|c|}
\hline $\begin{array}{l}\text { Dimension of } \\
\text { interdependence } \\
\text { construction: time-space } \\
\text { distanciation by stored } \\
\text { resources }\end{array}$ & $\begin{array}{l}\text { What kind of information and communication is } \\
\text { involved? } \\
\text { Contextual, stored information and communica- } \\
\text { tion, significant due to the connection to stored } \\
\text { resources. }\end{array}$ \\
\hline $\begin{array}{l}\text { Specifics of CIT: } \\
\text { CIT relaxes the conditions of } \\
\text { access significantly: high } \\
\text { accessibility of information } \\
\text { and related communication. } \\
\text { Permanence and publicity of } \\
\text { written information and } \\
\text { communication. } \\
\text { Overview aids } \\
\text { comprehending the } \\
\text { information as a whole. }\end{array}$ & $\begin{array}{l}\text { Time-space distanciation in the cases: } \\
\text { Significant, often large collections of information } \\
\text { became used as a resource increasingly or in a } \\
\text { novel way. This contributed to the persistence of } \\
\text { the interdependent group. } \\
\text { Additional insight provided by the cases: } \\
\text { Zeta: Awareness of shared responsibility of } \\
\text { information; reconfiguring interdependence } \\
\text { relations from reactive to proactive. } \\
\text { Eiger: Resources became discussable and } \\
\text { interaction gained new dimensions, which resulted } \\
\text { in denser reciprocity. } \\
\text { CCC: CIT-supported possibility for overview. } \\
\text { The perceived advantages of having high access to } \\
\text { information and communication encouraged start } \\
\text { of use. }\end{array}$ \\
\hline
\end{tabular}




\subsection{Institutionalization and History of Interaction}

In CCC, the history of interaction was significant for the emergence and establishment of collaborative decision making practice and compliance to joint decisions. Individual consultants could (and did) act against the decisions made in meetings, even against those they had participated in making. Several measures were taken to make the decision making and implementation more effective. Meeting agendas and minutes were entered in Notes. After about two years of use, a consultant stated that the meeting minutes had become a very valuable resource for managing the decision making process in the company: if well recorded, they would provide the backing that was sometimes needed for implementing decisions. However, what probably was more influential for the openness of managing the company was the gradual transfer of discussions from meetings into Notes databases. Thus the consultants gradually started complying with the decisions, as the processes became more transparent and more established because the accounts of the discussions and decisions were permanently and publicly available in Notes.

In Zeta, an incident history field was implemented in the call record application ITSS. The person updating the incident record was asked to enter what was done and what would be required next. ITSS then appended a time stamp and an identification of the person who had done the update. Nothing entered into the history field could be deleted. This led to some self-censorship on the part of the specialists, as the whole history of the call could be easily read by others. The work process became documented and an audit trail was generated by which the specialists would became accountable not only for output but also for work in progress. The supervisors monitored the work by reading what was entered in the call records. Also, informal norms for free text fields gradually evolved. These norms reflected a recognition of the database as a shared resource and an observation that its value lay in making the contents of incident records reusable. The practices of interdependence via call records became gradually so established that they became taken for granted and a basis for further changes in work practices. Examples of these are the previously mentioned case of proactive help and the new practice of making model cases of common types of problems.

In Eiger, as the interdependence relations became more pronounced, the interaction via CIT became more cryptic and shortened. In parallel, the number and length of messages decreased, and fewer iterations were required to settle an issue, as understanding among the participants improved. To quote one designer (in the USA): "The more you know the programmer (in Asia), the less you may need to write effectively with him." Ngwenyama (1998, p. 138) interpreted this development as building up a shared context of meaning, despite the geographic and cultural distance. It can also be read as creating significant stocks of mutual knowledge, as the participants in the discussion had past interactions available. A similar phenomenon also took place in CCC, where messages started to appear in the midst of a project record. This was possible because of reading through all new entries with the scan unread command. When read in this way, instead of opening each database separately and finding changed entries, the process of informing became one undifferentiated flow, an ongoing conversation around documents and issues, quite similar to what had taken place before in the meetings. A consequence of this practice was also that gradually the databases became "an incomprehensible mess" for those reading them in some other way. 
Both in Eiger and in $\mathrm{CCC}$, the institutionalized practices thus tended to further integrate the participants by the coded form of the interactions that acted as a barrier to outsiders. Even though the interaction was inscribed in the database entries, they were not entered for the purpose of later use as a consultable record, as in Zeta. There the clarity of entries and agreed conventions became focal, as the entries became resources to be used in future problem solving. In this way, they became actively constructed history. In terms of the nature of institutionalization, this difference between task at hand and consultable record is important. In Eiger and CCC, the practices became institutionalized as "our practices" and they provided the difference between "us" and "them." In Zeta, the institutionalization was more formal and regulated as the aim was to establish personindependent systems of interaction.

Table 4. The Third Dimension: Institutionalization of Practices

\begin{tabular}{|l|l|}
\hline $\begin{array}{l}\text { Dimension of } \\
\text { interdependence } \\
\text { construction: } \\
\text { Institutionalization of } \\
\text { practices }\end{array}$ & $\begin{array}{l}\text { What kind of information and communication is } \\
\text { involved? } \\
\text { Permanently and publicly available history of } \\
\text { interaction is focal in institutionalization of } \\
\text { practices. }\end{array}$ \\
\hline $\begin{array}{l}\text { Specifics of CIT: } \\
\text { practices as actions are } \\
\text { shown in the stored } \\
\text { information and } \\
\text { communication. }\end{array}$ & $\begin{array}{l}\text { Institutionalization of practices in the cases: } \\
\text { Significant stocks of knowledge were built as the } \\
\text { history of interaction started accumulating. } \\
\text { Interdependent work practices became established, } \\
\text { using these as their key resource. The } \\
\text { institutionalized practices tended to further } \\
\text { integrate the participants by the coded form of } \\
\text { interactions that acted as a barrier to outsiders. }\end{array}$ \\
& $\begin{array}{l}\text { Additional insight provided by the cases: } \\
\text { CCC: Institutionalization of participatory decision } \\
\text { making due to increased transparency, given by } \\
\text { history of interaction being permanently and } \\
\text { publicly available. } \\
\text { Eiger: The more pronounced the interdependence } \\
\text { relationships, the more cryptic and concise the } \\
\text { CIT-mediated interaction became, and the fewer } \\
\text { iterations were needed. } \\
\text { Zeta: Permanence of record resulted in } \\
\text { accountability not only of completed work but also } \\
\text { work in progress. Reusability of call records made } \\
\text { it important to construct them robustly. Actively } \\
\text { constructed history. }\end{array}$ \\
\hline
\end{tabular}




\subsection{System Integration and Reciprocity}

In Eiger, neither access to information nor surveillance by using the information were open for negotiation. Senior management wanted to ensure that access to information was restricted and a complex set of authorization structures was designed to limit different classes of users to specific areas of the application and the databases. All team members had read-access to design documents, but update-access was determined by project responsibilities. However, the designers in the USA and the programmers in Asia were free to communicate by e-mail. They negotiated the nature of their reciprocity by discussing it in a separate communication channel. While previously the finished software design had been simply sent to Asia to be implemented, with this separate, noncontrolled communication, the design could be rendered open and negotiable. As the designers and programmers learned more about each others' competencies as they engaged in, for example, the reasoning behind particular designs or implementation, mutual appreciation for each others' skills and trust in them became clearly visible in the e-mail exchanges.

In Zeta, access to the ITSS database was free. A consequence was that the specialists became aware of this mutual surveillance or "big brother." The possibility of scrutiny focused specialists' attention on (and possibly modification of) what impression they conveyed of themselves in electronic text. Orlikowski refers to this self-regulation as a form of "participatory surveillance" (Poster 1990). A subtler point brought up by Orlikowski, as informed by Foucault (1979, pp. 202-203), is that by being knowingly electronically visible, the specialists participated in defining the constraints of power to which they were subjected.

As in Eiger, the Zeta specialists could not influence the access that others had to their "textualized work." What they could influence, however, was what they would disclose themselves. The ITSS call entries provided a "brag-record" for high performers, a showcase for their efforts, embellished or not. Orlikowski interpreted this as a subtle shift in the texture of work, into an interest in symbolic artifacts that describe execution of work, immediately and continually available through the technology. The negotiation of mutuality had proceeded relatively smoothly within the original department, but when access to the ITSS database was planned to be given to others, as well, concerns arose about access to and use of the information. The solution was to make only edited versions of key topics available. Both consciousness of self and consciousness of "us" thus lead to highly managed disclosure.

In CCC, the negotiation of mutuality was perhaps the clearest of the three cases because the consultants had full control over what they entered into the databases. At first, only a few of the consultants entered their project information regularly. A key Notes champion also entered information on behalf of non-Notes users until everybody had developed a regular usage pattern. Awareness of the information in the databases also led to awareness of how they were becoming increasingly visible to each other. At first, only information that was considered useful to the others was entered. As the information in the databases was kept confidential, those who had initially entered only a minimum of information gradually came to reveal more of their activities. Disclosure in Notes always lagged some distance behind the face-to-face interdependence practices, but the experiences during the recession had convinced even the more reluctant ones of the benefits of being "in the know." 
Table 5. The Fourth Dimension: System Integration and Reciprocity

\begin{tabular}{|l|l|}
\hline $\begin{array}{l}\text { Dimension of interdependence } \\
\text { construction: } \\
\text { reciprocity integration and }\end{array}$ & $\begin{array}{l}\text { What kind of information and communication is } \\
\text { involved? } \\
\text { Mutually accessible and maintainable informa- } \\
\text { tion, together with the negotiated forms of } \\
\text { reciprocity, may result in ownership and respon- } \\
\text { sibility for the information. Visibility and control } \\
\text { between collectivities is managed by negotiating } \\
\text { the extent of surveillance and disclosure of } \\
\text { information. }\end{array}$ \\
\hline $\begin{array}{l}\text { Specifics of CIT: } \\
\text { means for information access, } \\
\text { disclosure, and maintenance. } \\
\text { Means for managing }\end{array}$ & $\begin{array}{l}\text { System integration in the cases: } \\
\text { By managed disclosure, the users could } \\
\text { influence how they were surveiled and hence } \\
\text { how they gave others the opportunity for control. } \\
\text { The possibility for mutual control turned into } \\
\text { mutual trust in CCC and Eiger, but into a more } \\
\text { formal system integration in Zeta. }\end{array}$ \\
$\begin{array}{ll}\text { Additional insight provided by the cases: } \\
\text { Eiger: Programmers and designers negotiated } \\
\text { the nature of their reciprocity by discussing it } \\
\text { outside the application. } \\
\text { Zeta: Awareness of mutual surveillance led to } \\
\text { self-regulation. Possibility to determine the } \\
\text { extent of own disclosure drew attention to } \\
\text { symbolic artifacts that describe execution of } \\
\text { work. } \\
\text { CCC: Need for mutual control was used to invite } \\
\text { disclosure. Experiences of mutual maintenance } \\
\text { with less risky information gradually led also to } \\
\text { disclosure of confidential information. }\end{array}$ \\
\hline
\end{tabular}

\section{Discussion and Conclusions}

The four aspects of interdependence construction were taken from structuration theory, which again rests on a considerable body of social research. Therefore, it seemed relatively safe to assume that structuration theory might offer the kind of processual approach that the problem area invited. Also, structuration theory attempts to bridge the everyday social practices to what is established or institutionalized in a social system, and in this way it had promise for studying interdependence relationships. The main impetus for choosing structuration theory was the comments about mediated communication and role of stored information in time-space distanciation with which Giddens had peppered his text. Since he has not followed himself on these lines, I took these as an invitation 
to give it a try. Even though structuration theory is very rich and it does not yield to appropriation easily, it proved fruitful for the work in this study. It was possible to construct a comprehensible (even if not comprehensive) account of the main processes of interdependence construction with it and to relate these to information and communication.

Information and communication appeared to be implicated in each of the four aspects as follows: First, social integration can take place not only in circumstances of copresence but also via situated mediated communication with sufficient social information. Second, stored resources with related information and communication make time-space distanciation possible, as they become persistent and highly accessible. Third, history of situated interaction contributes to the institutionalization of interdependence relationships, as it gives a basis for comparing present to past action. And fourth, practices of reciprocity in relation to information and those of surveillance and disclosure contribute to system integration by allowing visibility and control between groups.

All of these aspects of interdependence construction appeared also to be linked with each other. Increased social and system integration meant increased reciprocity of practices, which is needed for time-space distanciation and institutionalization of practices. Information and communication play several roles in these connections. For example, access to significant information is not only a way to the stored (material) resources the information is about but also to the actions of other people in the group. Available history of past interaction can contribute to building significant stocks of mutual knowledge which can then not only ground the relationships but also support coordinated action. When information and communication is significant and highly accessible, it is also likely to be more controllable. Accessible information is also discussable, and these discussions contribute to increased reciprocity. The cases gave ample evidence of how these connections worked in practice.

The collaborative information technology that was used in each of the cases was Lotus Notes. However, the installations differed significantly in terms of number of users, applications in use, way of appropriation (discretionary in CCC, mandatory in the two others), extent of use, etc. Regardless of these differences, several common features or phenomena were found in all cases. Among others, possibility for situated interaction with related social information, high accessibility, accessible account of the past interactions, and managed disclosure were identified. Revisiting the cases appeared fruitful, as they gave the work empirical grounding and also opened unanticipated vistas.

To sum up, the theory introduced here provides a way to understand the complex relationship between (emergent) collaboration and collaborative information technology. By it we can move away from the dilemmas of causality between collaboration and CIT. Also, the theory provides a more specific characterization of the relationship than approaches that focus merely on emergent processes or collaborative IT in general. The key insight of the theory is to connect these by information and communication, and thus it is able to provide a plausible account of their relationship. Further work on the theory will both relate it to current IS/CSCW research and use it to inform empirical studies. 


\section{Acknowledgments}

Matthew Jones, Andrew Brown, Geoff Walsham, Kalle Lyytinen, Juhani Iivari, Matti Rossi, Uta Pankoke-Babatz, Markus Ritterbruch, and Helge Kahler gave very valuable feedback while I worked on the first versions of this article. I have given short presentations of (some of) these ideas in Cambridge, Copenhagen, and Jyväskylä. I thank all participants for lively and challenging discussions. The reviewers of the WG8.2 conference also gave very useful criticism: many thanks for their efforts.

\section{References}

Attewell, P. "Technology Diffusion and Organizational Learning: The Case of Business Computing," Organization Science (3:1), 1992, pp. 1-19.

Barley, S. R. "The Alignment of Technology and Structure through Roles and Networks," Administrative Science Quarterly (35), 1990, pp. 61-103.

Berger, P. L., and Luckmann, T. The Social Construction of Reality. Garden City, NY: Doubleday, 1967.

Buscher, M., and Mogensen, P. H. "Mediating Change: Translation and Mediation in the Context of Bricolage," in Facilitating Technology Transfer through Partnership: Learning from Practice and Research, T. McMaster, E. Mumford, E. B. Swanson, B. Warboys, and D. Wastell (eds.). London: Chapman \& Hall, 1997, pp. 76-91.

Button, G., and Sharrock, W. "The Production of Order and the Order of Production: Possibilities for Distributed Organizations, Work and Technology in the Print Industry," paper delivered at the European Conference on Computer-supported Cooperative Work (ECSCW'97), Lancaster, UK, 1997.

Clement, A., and Wagner, I. "Fragmented Exchange: Disarticulation and the Need for Regionalized Communication Spaces," in Proceedings of the Fourth European Conference on Computer-supported Cooperative Work (ECSCW'95), H. Marmolin, Y. Sundblad, and K. Schmidt (eds.). Dordrecht, The Netherlands: Kluwer, 1995, pp. 33-49.

Coleman, D. Electronic Collaboration on the Internet and Intranets. San Fransisco: Collaborative Strategies, 1996 (http://www.collaborate.com/intranet.html).

Connolly, T., and Thorn, B. K. "Discretionary Databases: Theory, Data, and Implications," in Organizations and Communication Technology, J. Fulk and C. Steinfield (eds.). London: Sage, 1990, pp. 219-233.

Daft, R. L., and Lengel, R. H. "Information Richness: A New Approach to Managerial Behavior and Organization Design," in Research in Organizational Behavior (Volume 6), B. M. Staw and L. L. Cummings (eds.). Greenwich, CT: JAI Press, 1984, pp. 191-233.

Daft, R. L., and Lengel, R. H. "Organizational Information Requirements, Media Richness and Structural Ddesign," Management Science (32), 1986, pp. 554-571.

Dennis, A. R., and Kinney, S. T. "Testing Media Richness Theory in the New Media: The Effects of Cues, Feedback, and Task Equivocality," Information Systems Research (9:3), 1998, pp. 256-274.

Dyson, E. "Why Groupware is Gaining Ground," Datamation, March 1, 1990, pp. 52-56.

El-Shinnawy, M., and Markus, L. "Acceptance of Communication Media in Organizations: Richness or Features?" IEEE Transactions on Professional Communication (41:4), 1998, pp. 242-253.

Foucault, M. Discipline and Punish. New York: Vintage Books, 1979. 
Gallivan, M., Goh, G. H., Hitt, L. M., and Wyner, G. Incident Tracking at Infocorp: Case Study of a Pilot NOTES Implementation. Working Paper No. 149, Center for Coordination Science, Sloan School of Management, Massachusetts Institute of Technology, Cambridge, MA, 1993.

Giddens, A. Central Problems in Social Theory: Action, Structure and Contradiction in Social Analysis. London: Macmillan, 1979.

Giddens, A. The Constitution of Society. Cambridge, England: Polity Press, 1984.

Giddens, A., and Pierson, C. Conversations with Anthony Giddens: Making Sense of Modernity. Cambridge, England: Polity Press, 1998.

Goffman, E. Interaction Ritual. London: Allen Lee, 1972.

Goody, J. The Interface between the Written and the Oral. Cambridge, England: Cambridge University Press, 1987.

Haraway, D. Simians, Cyborgs, and Women: The Reinvention of Culture. London: Free Association Books, 1991.

Joerges, B. "Technology in Everyday Life: Conceptual Queries," Journal for the Theory of Social Behavior (18:2), 1988, pp. 219-237.

Jones, M. R. "Structuration Theory," in Re-thinking Management Information Systems, W. J. Currie and R. Galliers (eds.). Oxford: Oxford University Press, 1999, pp. 103-135.

Jones, M. R., and Karsten, H. "Collaborative Information Technology and New Organizational Forms: A Case of a Consulting Firm," paper delivered at the Pacific Asia Conference on Information Systems (PACIS'97), Brisbane, Australia, 1997.

Karsten, H. "Converging Paths to Notes: In Search for Computer-based Information Systems in a Networked Company," Information Technology and People (8:1), 1, 1995, pp. 7-34.

Karsten, H. "Relationship between Organizational Form and Organizational Memory: An Investigation in a Professional Service Organization," Journal of Organizational Computing and Electronic Commerce, Special Issue on Organizational Memory Systems (9:2), 1999, pp. 129-150.

Karsten, H., and Jones, M. "The Long and Winding Road: Collaborative IT and Organizational Change," paper delivered at the Conference on Computer Supported Cooperative Work (CSCW'98), Seattle, WA, November 16-18 1998.

Kling, R. "Cooperation, Coordination and Control in Computer-supported Work," Communications of the ACM (34:12), 1991, pp. 83-88.

Kock, N. "Can Communication Medium Limitations Foster Better Group Outcomes? An Action Research Study," Information \& Management (34:5), 1998, pp. 295-305.

Latour, B. On Technical Mediation: The Messenger Lectures on the Evolution of Civilization, Cornell University, April 1993. Working Paper ISRN LUSADG/ IFEF/WPS-93/9-SE. Lund, Sweden: Lund University, 1993.

Lave, J., and Wenger, E. Situated Learning: Legitimate Peripheral Participation. New York: Cambridge University Press, 1991.

Lyytinen, K., and Ngwenyama, O. "What Does Computer Support for Cooperative Work Mean? A Structurational Analysis of Computer Supported Cooperative Work," Accounting, Management, \& Information Technology (2:1), 1992, pp. 19-37.

Mintzberg, H. The Structuring of Organizations. Englewood Cliffs, NJ: Prentice Hall, 1979.

Ngwenyama, O. Breakdowns and Innovations in Computer Mediated Work: Groupware and the Reproduction of Organizational Knowledge, unpublished manuscript, University of Michigan Business School, Ann Arbor, MI, 1996.

Ngwenyama, O. "Groupware, Social Action and Emergent Organizations: On the Process Dynamics of Computer Mediated Distributed Work," Accounting, Management, \& Information Technology (8:4), 1998, pp. 123-143.

Orlikowski, W. J. Evolving with Notes: Organizational Change Around Groupware Technology, Working Paper 186, Center for Coordination Science, Sloan School of Management, Massachusetts Institute of Technology, Cambridge, MA, June 1995. 
Orlikowski, W. J. "Improvising Organizational Transformation Over Time: A Situated Change Perspective," Information Systems Research (7:1), 1996, pp. 63-92.

Poster, M. The Mode of Information: Poststructuralism and Social Context. Chicago: University of Chicago Press, 1990.

Poster, M. The Second Media Age. Cambridge, England: Polity Press, 1995.

Prinz, W., Mark, G., and Pankoke-Babatz, U. "Designing Groupware for Congruency in Use." paper delivered at the Conference on Computer Supported Cooperative Work (CSCW'98), Seattle, WA, November 16-18, 1998.

Robinson, M. "Computer Supported Cooperative Work: Cases and Concepts," in Readings in Groupware and Computer Supported Cooperative Work, R. Baecker (ed.). Palo Alto, CA: Morgan Kaufman, 1991.

Rogers, Y. "Exploring Obstacles: Integrating CSCW in Evolving Organizations," in Proceedings of Conference on Computer Supported Cooperative Work (CSCW'94), Chapel Hill, NC, 1994, pp. 67-77.

Schmidt, K. "Of Maps and Scripts: The Status of Formal Constructs in Cooperative Work," paper delivered at the GROUP'97 ACM Conference on Supporting Group Work, Phoenix, AZ, 1997.

Sproull, L., and Kiesler, S. Connections: New Ways of Working in the Networked Organization. Cambridge, MA: MIT Press, 1991.

Suchman, L. Plans and Situated Action. Cambridge, England: Cambridge University Press, 1987.

Swanson, E. B., and Ramiller, N. C. "The Organizing Vision in Information Systems Innovation," Organization Science (8:5), 1997, pp. 458-474.

VanHouse, N. A., Butler, M. H., and Schiff, L. R. "Cooperative Knowledge Work and Practices of Trust: Sharing Environmental Planning Data Sets," paper delivered at the Conference on Computer Supported Cooperative Work (CSCW'98), Seattle, WA, 1998.

Weick, K. E. The Social Psychology of Organizing. Reading, MA: Addison-Wesley, 1979.

Zuboff, S. In the Age of the Smart Machine. New York: Basic Books, 1988.

\section{About the Author}

Helena Karsten works in the Grouptechnologies Program at the Department of Computer Science and Information Systems at the University of Jyväskylä. Her long-term interests have been appropriation and use of collaborative information technologies, and structuration theory. A current project is Globe, together with Kalle Lyytinen and Ojelanki Ngwenyama. In Globe, the concern is in managing large projects at Valmet, a major paper machinery supplier. Helena can be reached by e-mail at eija@jytko.jyu.fi. 